\title{
Evaluation of Non-Carcinogenic Risk of Pb, Cd, and As in Air Suspended Particles of Baharestan City, Isfahan
}

\author{
Amir Hossein Baghaie ${ }^{1,{ }^{*}}$ and Ardeshir Khosravi-Dehkordi ${ }^{2}$ \\ ${ }^{1}$ Department of Soil Sciences, Arak Branch, Islamic Azad University, Arak, Iran \\ ${ }^{2}$ Department of Environmental Sciences, Faculty of Natural Resources, Isfahan University of Technology, Isfahan, Iran \\ "Corresponding author: Department of Soil Sciences, Arak Branch, Islamic Azad University, Arak, Iran. Email: a-baghaie@iau-arak.ac.ir
}

Received 2018 October 30; Revised 2019 January 04; Accepted 2019 January 29.

\begin{abstract}
Background: Entrance of heavy metals into the respiratory system has adverse effects on human health. Accordingly, measuring metals concentration in places and times is necessary.

Objectives: This study was done to evaluate the non-carcinogenic risk of $\mathrm{Pb}, \mathrm{Cd}$, and As in air suspended particles of Baharestan city, in Isfahan, during 2016 - 2017.

Methods: In order to evaluate the non-carcinogenic risk of heavy metals in air suspended particles $\left(\mathrm{PM}_{10}\right)$, sampling was performed using a SKC pump with a low volume $(1.5 \mathrm{~L} / \mathrm{min})$ and $37 \mathrm{~mm}$ membrane filter. Sampling was carried out on average every three days during 24-hours in May - June, July - August, October - November, and January - February; finally, the concentration of Pb, Cd, and As was determined using atomic absorption spectrometry (AAS) and hydride generation atomic absorption spectrometry (HGAAS), respectively. The acute and chronic non-carcinogenic risk of heavy metals sorption in the air was evaluated using the EPA method. Results: The highest and lowest $\mathrm{Pb}$ concentration belonged to May - June and October - November, with the mean concentration of 0.25 and $0.14 \mathrm{mg} / \mathrm{kg}$, respectively. For Cd it was 0.017 and $0.009 \mathrm{mg} / \mathrm{kg}$, respectively. Similar results were found for the air suspended particles. The highest and lowest Cd non-carcinogenic risk was observed for permanent residents of Baharestan city and the nondormitory students of this city with the mean of $3.1 \times 10^{-5}$ and $1.4 \times 10^{-5}$, respectively.

Conclusions: The results of this study showed that the non-carcinogenic risk of heavy metals was lower than the standard level during the study years. However, heavy metal accumulation can threaten human health, which needs more consideration.
\end{abstract}

Keywords: Non- Carcinogenic Risk, Pb, As, Cd, Baharestan

\section{Background}

The industrial advances and the mechanization of human life in different societies have never been without any harm or effect. Air pollution in industrial areas seriously threatens the human health and therefore, it is more and more considered by the researchers (1-3). Among the air pollutants, suspended particles, especially in large cities, has been increasingly considered $(4,5)$.

Suspended particles are dangerous for human health at high concentrations, for example, they cause different diseases such as upper respiratory tract infection, pulmonary inflammation, and bronchitis $(6,7)$. Heavy metals are one group of compounds present in the air with a high risk for human health $(8,9)$. The presence of heavy metals in greater concentration than the standard levels causes environmental problems and damages the inhabitant's health of that site and the ecosystem $(10,11)$. Heavy metals have different effects on human health such as neurological disorders, different types of cancers, and skeletal problems. On the other hand, the ability of bio-accumulation of heavy metals in plants and animals and their entry into the food chain will increase the risk of their toxicity $(12,13)$. Considering the environmental problems of heavy metals on air quality, measuring the concentration of these elements in the air and assessing their potential health risk is necessary (14).

Risk assessment is a process in which the potential health risk is estimated (15). Environmental management decisions are based on the risk assessment and risk management. Generally, risk assessment provides scientific principles for environmental legislation. The general objectives of risk assessment are the attention to the state of soil, air, water, or sediment contamination, the study of all 
possible ways, which cause the organisms exposure to contamination sources, estimate the amount of pollutants entering the body of living organisms (16-18), and determining the negative effects of contaminant on organisms.

The risk assessment of heavy metals was investigated in four stages: Hazard identification, assessment of the baseline value, considering the contact pathway, and finally determining the risk index. Firstly, the harmful effects of chemical materials on human health are recognized. Then, the basic level is determined for the pathogenicity of the elements. In the third step, various ways of contacting chemicals, i.e. sorption from the oral or the skin pathway and inhalation of suspended particles are investigated. Finally, the risk factor for carcinogenic and non-carcinogenic diseases is determined (19).

Barin and Chavoshi investigated the risk of $\mathrm{Cu}$ and $\mathrm{Zn}$ in wheat and rice (with the mean concentration of 8.4 and $11.4 \mathrm{mg} / \mathrm{kg}$, respectively) cultivated around the Irankouh mine in Isfahan and concluded that the consumption of these products does not have any problem for the human body (19). Shafie-Pour et al. evaluated the air pollution risk of the Beihaqi Passenger Terminal by modeling method and reported that the non-carcinogenic risk from heavy metals sorption for drivers and terminal staff was higher than the safe level (20). Noorpoor and Sadri Jahanshahi determined the risk of heavy metals in the air of Tehran's Enghelab street, and reported that the non-carcinogenic risk index, as a result of entering heavy metals into the breathing system, is below the safety level (21). Studies on airborne diseases show that more than 2 million early deaths per year (more than $50 \%$ of deaths are attributed to the Asian continent) are due to air pollution. More than half of the deaths are attributable to industrialized and developing countries (22).

Indicators such as air quality index (AQI) are often used to indicate air pollution, which is designated by the environmental protection agency (EPA). The main purpose of these indicators is to determine the effects of air pollution on human health. The AQI indicator is usually used to determine the amount of five different pollutants, such as $\mathrm{PM}_{10}, \mathrm{NO}_{2}, \mathrm{SO}_{2}, \mathrm{O}_{3}$, and $\mathrm{CO}(23)$. Majlesi Nasr et al. investigated air pollutant concentrations and air quality index in Shiraz during 2011 - 2013 and concluded that $\mathrm{NO}_{2}$ concentration was increased due to the fact that the number of gas fuel automobile also increased (23). Allahyari et al. with the study of air pollution condition and comparing in different areas of Mashhad in winter 2011, mentioned that AQI index can be a good factor to indicate air pollution condition (24).
Baharestan is located $20 \mathrm{~km}$ southeast of Isfahan, along the Isfahan-Shiraz road, with a population of about 79000 , and with three universities. It is noted that in the city of Baharestan, there is not only no data regarding the state of air pollution to heavy metals, however, also no monitoring station for investigation air quality. Considering the population increasing in this city as well as the existence of universities and industrial offices, such as the Mobarakeh industrial zone in this area, it is necessary to study the status of air pollution to heavy metals in this region.

\section{Objectives}

This study was conducted to evaluate the noncarcinogenic risk of $\mathrm{Pb}, \mathrm{Cd}$, and $\mathrm{As}$ in air suspended particles in Baharestan city during 2016 - 2017.

\section{Methods}

In order to determine the concentration of $\mathrm{Pb}, \mathrm{Cd}$, and As, sampling of the air suspended particle $\left(\mathrm{PM}_{10}\right)$ in the first phase of Baharestan (between the entrance of Baharestan until Valiasr square) was carried out during 2016 - 2017. Sampling was performed using the SKC pump with a low volume (1.5 L/min) and a $37 \mathrm{~mm}$ membrane filter (25). Sampling was done on average every three days during 24 hours in May - June, July - August, October - November, and January - February, and finally the concentration of heavy metals of $\mathrm{Pb}$ and $\mathrm{Cd}$ was determined using atomic absorption spectrometry (AAS) after digesting with three acids (perchloric acid, fluoroboric acid, and chloride acid); according to Hosseini et al. (25). It is mentioned that for measuring As, the hydride generation atomic absorption spectrometry (HGAAS) was used. It should be noted that sampling was also done during the days that were announced by the Meteorological Organization as dusty days $(25,26)$. In total, 61 samples were taken; 40 days were non-dusty days (concentrations less than $250 \mu \mathrm{g} / \mathrm{m}^{3}$ ) and 21 days were dusty days (27) (particle concentration below $250 \mu \mathrm{g} / \mathrm{m}^{3}$ ).

$\mathrm{The} \mathrm{Pb}, \mathrm{Cd}$, and As non-carcinogenic hazard quotient (HQ) was calculated into two groups (acute and chronic effects base on the reference concentration (RFC)) using the Equation 1(25, 28):

$$
H Q=C D I / R F C
$$

Where CDI is the amount of heavy metals daily sorption ( $\mathrm{mg} / \mathrm{kg}$ body weight per day) via inhalation pathway, which was calculated by the Equation 2:

$C D I=(C A \times E F \times E D) / A T$ 
Where:

CA: Heavy metal concentration $\left(\mu \mathrm{g} / \mathrm{m}^{3}\right)$

EF: Exposure frequency (days year ${ }^{-1}$ ): In this study, it was assumed to be 360 and 180 days in the year for permanent resident and students, respectively.

ED: The exposure duration (y): A 30 and 4 years duration was considered for permanent residents and dormitory or non-dormitory students of Baharestan University, respectively.

ET: The daily exposure hours: This was assumed 24 hours per day for permanent residents (group 1), dormitory students (group 2), and 8 hours per day for nondormitory students (group 3 ).

AT: The averaging time (day) for non-carcinogenic effects $(\mathrm{ED} \times 365)$

In this study, the evaluation of non-carcinogenic chronic risk was calculated based on the reference concentration (RFC) for $\mathrm{Pb}, \mathrm{Cd}$, and As, which was $1.5 \times 10^{-1}, 1.0 \times$ $10^{-2}$, and $1.5 \times 10^{-2} \mu \mathrm{g} / \mathrm{m}^{3}$, respectively. The reference concentration (RFC) for non-carcinogenic acute risk of $\mathrm{Cd}$ and As was $3.0 \times 10^{-2}$ and $2.0 \times 10^{-1} \mu \mathrm{g} / \mathrm{m}^{3}$, respectively (25).

Air quality index (AQI), according to the suspended particle $\left(\mathrm{PM}_{10}\right)$, was calculated as it was mentioned by Heidarinejad et al. (29).

\section{Results}

Regardless the studied years, the highest concentration of $\mathrm{PM}_{10}$ particles was observed in May - June while the lowest amount of that was in July - August (Table 1). In addition, the concentration of $\mathrm{PM}_{10}$ particles significantly increased in 2017 as compared to 2016. The similar results were observed for AQI index (Table 1).

The heavy metals concentration was higher in dusty comparative to non-dusty days (Table 2). The highest and lowest heavy metals concentration in the air was observed in May-June and October - November, respectively. Regardless of months and years, As and Cd had the greatest and lowest concentration, respectively. Heavy metals concentration increased significantly in 2017 relative to 2016.

The highest and lowest acute or chronic noncarcinogenic risk of heavy metals belonged to As and Cd, respectively, which increased in 2017 relative to 2016. It should be noted that among the groups studied (group 1, 2 and 3), the highest and lowest chronic and acute noncarcinogenic risk was observed in group one and three, respectively (Tables 3 and 4).

\section{Discussion}

As mentioned, the highest AQI index, based on $\mathrm{PM}_{10}$ suspended particles was observed in May - June, which is categorized in an unhealthy group for all individuals (31). In January - February, it was unhealthy for susceptible and general individuals, based on the AQI index (32) during 2016 and 2017, respectively. The increasing of $\mathrm{PM}_{10}$ suspended particle can be related to the decrease in rainfall during the studied years. Reducing rainfall by increasing soil erosion can increase the amount of suspended particles in the air, which can be dangerous for human health (25). However, the role of decreasing temperature and air inversion phenomenon on increasing suspended particles in January - February cannot be ignored (32). The similar results for the concentration of heavy metals confirm this matter clearly. The lowest $\mathrm{PM}_{10}$ particles in the present study were between October - November, which may be due to the humidity increasing in these months. It should be noted that in October - November, the AQI index was classified as the clean air (33) and the amount of $\mathrm{PM}_{10}$ was below the standard level (34).

Moattar et al. investigated the amount of heavy metals in the airborne of Atomic Energy Agency site and reported that the increasing heavy metal concentration in January - February could be related to the inversion phenomenon. However, the concentration of heavy metals studied in their research was below the standard level (32). According to their results, the highest and lowest heavy metal concentration belonged to the winter and autumn season (32), which is very similar to our results.

The concentration of heavy metals in dusty relative to non-dusty days showed a significant difference $(P=0.05)$, indicating that airborne particles could be a significant factor in the transferring of pollutants, where the origin of this pollutant could be due to the soil pollution or different industrial activities in the zone (35). Hosseini et al. evaluated the health risks of airborne heavy metal particles in the Kurdistan University of Medical Sciences and reported that the highest $\mathrm{PM}_{10}$ particles was in May - June, which could be related to the dust events in the middle east, which also reduce the Sanandaj air quality (25). Farahmand Kia et al. studied the heavy metals in the atmospheric deposition in Zanjan, west of Iran, and concluded that the industrial sources of heavy metals play the main role in concentration of heavy metals in wet and dry atmospheric precipitation in Zanjan (36).

Nazarpur et al. investigated the $\mathrm{Pb}$ and $\mathrm{Cd}$ accumulation on the surface leaves of pine trees in the cold and hot seasons and reported that the greater heavy metal concen- 


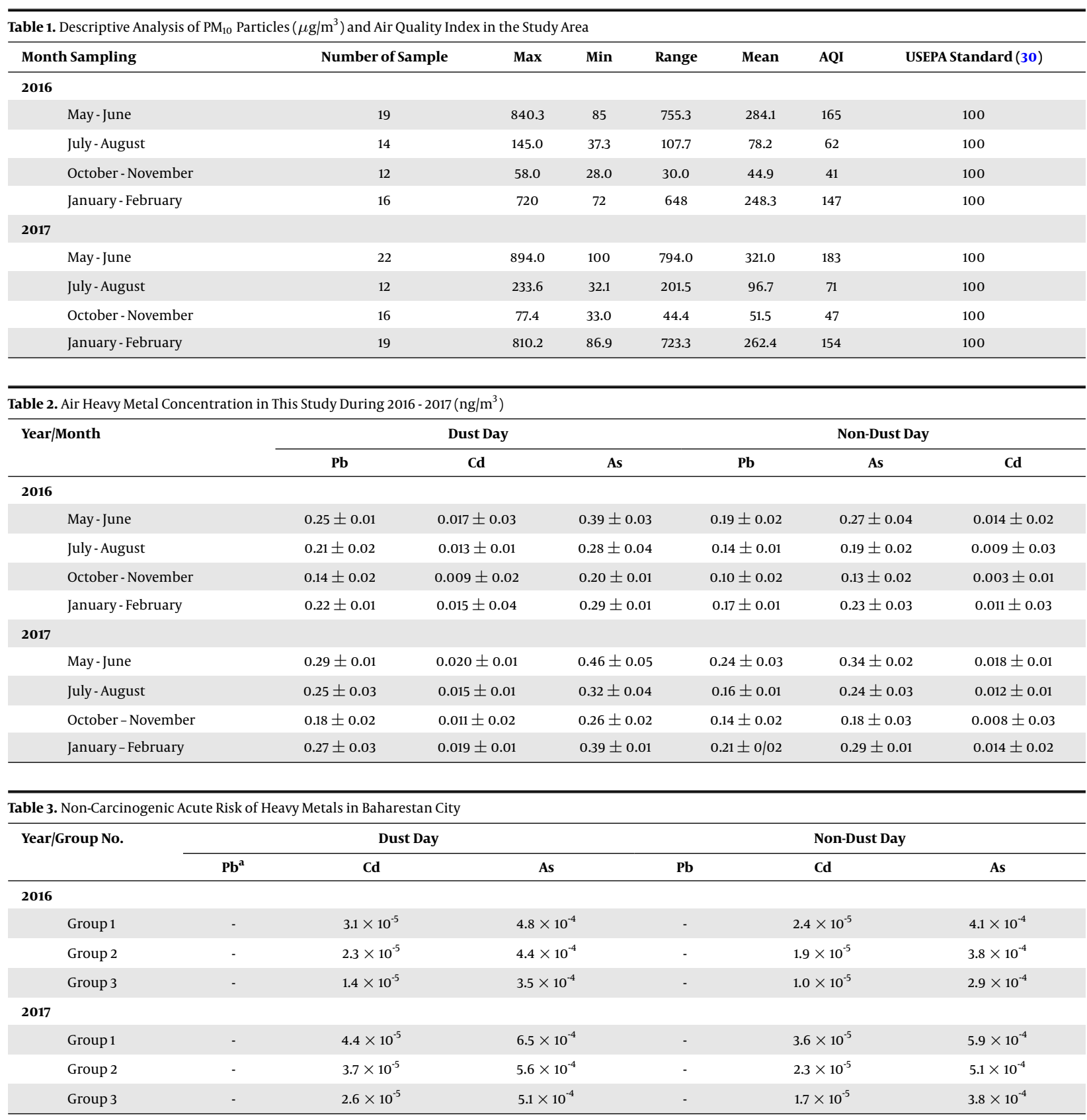

${ }^{\mathrm{a}}$ It is not calculated as the reference concentration (RFC) value for lead is not available.

trations on the surface of pine leaves was observed in the cold season, which may be due to the air inversion (37).

Based on the results, the non-carcinogenic risk of As is higher than that for $\mathrm{Cd}$, although these are below the standard level (25), indicating that As and Cd concentration in the air studied does not pose a high risk of noncarcinogenic diseases.

Regardless of the element type, the highest and low- est risk of acute non-cancerous diseases was in permanent residents and non-dormitory students with the most and the least hours of contact with the region air, respectively. However, the non-carcinogenic risk was below the standard level (25). The non-carcinogenic risk in non-dusty days has been decreased relative to dusty days, which is consistent with reducing the heavy metals concentration in non-dusty days. 


\begin{tabular}{|c|c|c|c|c|c|c|}
\hline Year/Group No. & \multicolumn{3}{|c|}{ Dust Day } & \multicolumn{3}{|c|}{ Non-Dust Day } \\
\hline & $\mathbf{P b}$ & Cd & As & $\mathbf{P b}$ & Cd & As \\
\hline \multicolumn{7}{|l|}{2016} \\
\hline Group 1 & $4.9 \times 10^{-5}$ & $4.2 \times 10^{-5}$ & $5.8 \times 10^{-4}$ & $4.1 \times 10^{-5}$ & $3.3 \times 10^{-5}$ & $4.7 \times 10^{-4}$ \\
\hline Group 2 & $3.7 \times 10^{-5}$ & $3.1 \times 10^{-5}$ & $5.1 \times 10^{-4}$ & $2.8 \times 10^{-5}$ & $2.4 \times 10^{-5}$ & $4.2 \times 10^{-4}$ \\
\hline Group 3 & $3.3 \times 10^{-5}$ & $2.5 \times 10^{-5}$ & $4.6 \times 10^{-4}$ & $2.4 \times 10^{-5}$ & $2.1 \times 10^{-5}$ & $3.5 \times 10^{-4}$ \\
\hline \multicolumn{7}{|l|}{2017} \\
\hline Group 1 & $5.7 \times 10^{-5}$ & $4.7 \times 10^{-5}$ & $6.4 \times 10^{-4}$ & $4.6 \times 10^{-5}$ & $4.1 \times 10^{-5}$ & $5.4 \times 10^{-4}$ \\
\hline Group 2 & $4.5 \times 10^{-5}$ & $3.9 \times 10^{-5}$ & $5.7 \times 10^{-4}$ & $3.4 \times 10^{-5}$ & $3.3 \times 10^{-5}$ & $4.9 \times 10^{-4}$ \\
\hline Group 3 & $3.9 \times 10^{-5}$ & $3.1 \times 10^{-5}$ & $5.1 \times 10^{-4}$ & $3.1 \times 10^{-5}$ & $2.8 \times 10^{-5}$ & $4.4 \times 10^{-4}$ \\
\hline
\end{tabular}

Ghanavati investigated the risk of heavy metals on human health in the street dust of Abadan and concluded that human activities play an important role in decreasing air quality. In addition, the risk of heavy metals in that area was higher than the standard level, in which this risk was higher in children than in adults (38). Shomali and Khodaverdilo investigated the risk of heavy metals in Kerman and concluded that the non-carcinogenic risk of heavy metals is more related to the pollution of motor vehicles (39).

The chronic non-carcinogenic risk of $\mathrm{Pb}$ and $\mathrm{Cd}$ in 2016 was observed in order of permanent residents $(\mathrm{Pb}=4.9 \times$ $\left.10^{-5}, \mathrm{Cd}=4.2 \times 10^{-5}\right)$, dormitory students $\left(\mathrm{Pb}=3.7 \times 10^{-5}, \mathrm{Cd}\right.$ $\left.=3.1 \times 10^{-5}\right)$, and non-dormitory students $\left(\mathrm{Pb}=3.3 \times 10^{-5}, \mathrm{Cd}\right.$ $\left.=2.5 \times 10^{-5}\right)$. It should be noted that due to the higher concentrations of As comparative to $\mathrm{Pb}$ and $\mathrm{Cd}$ in respiratory air, the highest non-carcinogenic risk was related to AS, although it was below the standard level.

It should be mentioned that the chronic noncarcinogenic index is greater than the acute noncarcinogenic index, however, they are lower than the standard level. The results of Hosseini et al. confirm this matter clearly (25). Noorpoor and Sadri Jahanshahi et al. mentioned the similar results for heavy metal non-carcinogenic effects of Tehran air (21).

\section{Acknowledgments}

The authors gratefully acknowledge the Islamic Azad University of Arak Branch for analyzing the samples.

\section{Footnotes}

Authors' Contribution: Amir Hossein Baghaie: Concept and design, writing the manuscript and revision, Ardeshir Khosravi-Dehkordi: Collection and analysis of data.

Conflict of Interests: Authors declared no conflict of interest.
Ethical Considerations: This research has not been a human or animal study.

Funding/Support: This research did not receive any specific grant from funding agencies in the public, commercial, or not-for-profit sectors.

\section{References}

1. Gordon T, Balakrishnan K, Dey S, Rajagopalan S, Thornburg J, Thurston G, et al. Air pollution health research priorities for India: Perspectives of the Indo-U.S. Communities of Researchers. Environ Int. 2018;119:100-8. doi:10.1016/j.envint.2018.06.013. [PubMed: 29944987].

2. Alimissis A, Philippopoulos K, Tzanis CG, Deligiorgi D. Spatial estimation of urban air pollution with the use of artificial neural network models. Atmos Environ. 2018;191:205-13. doi: 10.1016/j.atmosenv.2018.07.058.

3. Giannadaki D, Giannakis E, Pozzer A, Lelieveld J. Estimating health and economic benefits of reductions in air pollution from agriculture. Sci Total Environ. 2018;622-623:1304-16. doi: 10.1016/j.scitotenv.2017.12.064. [PubMed: 29890597].

4. Chen S, Guo C, Huang X. Air pollution, student health, and school absences: Evidence from China. J Environ Econ Manage. 2018;92:465-97. doi: 10.1016/j.jeem.2018.10.002.

5. Zhang Y, Qu S, Zhao J, Zhu G, Zhang Y, Lu X, et al. Quantifying regional consumption-based health impacts attributable to ambient air pollution in China. Environ Int. 2018;112:100-6. doi: 10.1016/j.envint.2017.12.021. [PubMed: 29268157].

6. Megido L, Suarez-Pena B, Negral L, Castrillon L, Fernandez-Nava Y. Suburban air quality: Human health hazard assessment of potentially toxic elements in PM10. Chemosphere. 2017;177:284-91. doi: 10.1016/j.chemosphere.2017.03.009. [PubMed: 28314233].

7. Gao Y, Ji H. Microscopic morphology and seasonal variation of health effect arising from heavy metals in PM2.5 and PM10: One-year measurement in a densely populated area of urban Beijing. Atmos Res. 2018;212:213-26. doi: 10.1016/j.atmosres.2018.04.027.

8. Maina EG, Gachanja AN, Gatari MJ, Price H. Demonstrating PM2.5 and road-side dust pollution by heavy metals along Thika superhighway in Kenya, sub-Saharan Africa. Environ Monit Assess. 2018;190(4):251. doi: 10.1007/s10661-018-6629-z. [PubMed: 29582158].

9. Talbi A, Kerchich Y, Kerbachi R, Boughedaoui M. Assessment of annual air pollution levels with PM1, PM2.5, PM10 and associated heavy metals in Algiers, Algeria. Environ Pollut. 2018;232:252-63. doi: 10.1016/j.envpol.2017.09.041. [PubMed: 28943349]. 
10. Yang J, Zhang B. Air pollution and healthcare expenditure: Implication for the benefit of air pollution control in China. Environ Int. 2018;120:443-55. doi: 10.1016/j.envint.2018.08.011. [PubMed: 30142582].

11. Landrigan PJ, Fuller R, Fisher S, Suk WA, Sly P, Chiles TC, et al. Pollution and children's health. Sci Total Environ. 2019;650(Pt 2):2389-94. doi: 10.1016/j.scitotenv.2018.09.375. [PubMed: 30292994].

12. Baki MA, Hossain MM, Akter J, Quraishi SB, Haque Shojib MF, Atique Ullah AKM, et al. Concentration of heavy metals in seafood (fishes, shrimp, lobster and crabs) and human health assessment in Saint Martin Island, Bangladesh. Ecotoxicol Environ Saf. 2018;159:153-63. doi: 10.1016/j.ecoenv.2018.04.035. [PubMed: 29747150].

13. Wu W, Wu P, Yang F, Sun DL, Zhang DX, Zhou YK. Assessment of heavy metal pollution and human health risks in urban soils around an electronics manufacturing facility. Sci Total Environ. 2018;630:53-61. doi: 10.1016/j.scitotenv.2018.02.183. [PubMed: 29475113].

14. Ravankhah N, Mirzaei R, Masoum S. [Human health risk assessment of heavy metals in surface soil]. J Mazandaran Univ Med Sci. 2016;26(136):109-20. Persian.

15. Kheirabadi H, Afyuni M, Ayoubi S, Soffianian A. [Risk assessment of heavy metals in soils and major food crops in the province of Hamadan]. J Water Soil Sci. 2016;19(74):27-38. Persian.

16. Doabi SA, Karami M, Afyuni M, Yeganeh M. Pollution and health risk assessment of heavy metals in agricultural soil, atmospheric dust and major food crops in Kermanshah province, Iran. Ecotoxicol Environ Saf. 2018;163:153-64. doi: 10.1016/j.ecoenv.2018.07.057. [PubMed: 30053585].

17. MohseniBandpi A, Eslami A, Ghaderpoori M, Shahsavani A, Jeihooni AK, Ghaderpoury A, et al. Health risk assessment of heavy metals on PM2.5 in Tehran air, Iran. Data Brief. 2018;17:347-55. doi: 10.1016/j.dib.2018.01.018. [PubMed: 29876404]. [PubMed Central: PMC5988319].

18. Sawut R, Kasim N, Maihemuti B, Hu L, Abliz A, Abdujappar A, et al. Pollution characteristics and health risk assessment of heavy metals in the vegetable bases of northwest China. Sci Total Environ. 2018;642:864-78. doi: 10.1016/j.scitotenv.2018.06.034. [PubMed: 29925057].

19. Barin M, Chavoshi E. [Risk assessment of zinc and copper exposure in rice, wheat and soil around Irankooh mine in Isfahan]. J Soil Manage Sustain Product. 2017;7(2):211-22. Persian. doi: 10.22069/ejsms.2017.10938.1637.

20. Shafie-Pour M, Pardakhti A, Mejari M. [Risk assessment of air pollutants emissions in beihaghi terminal by modeling]. J Environ Stud. 2015;41(1):97-105. Persian. doi:10.22059/jes.2015.53903.

21. Noorpoor AR, Sadri Jahanshahi A. [Evaluation of health risk assessment by heavy metals in the ambient air of Tehran]. J Environ Stud. 2014;39(4):181-92. Persian. doi: 10.22059/jes.2014.36471.

22. Im U, Brandt J, Geels C, Hansen KM, Christensen JH, Andersen MS, et al. Assessment and economic valuation of air pollution impacts on human health over Europe and the United States as calculated by a multi-model ensemble in the framework of AQMEII3. Atmos Chem Phys. 2018;18(8):5967-89. doi: 10.5194/acp-18-5967-2018. [PubMed: 30079086]. [PubMed Central: PMC6070159].

23. Majlesi Nasr M, Ansarizadeh M, Leili M. The assessment of air pollutant concentrations and air quality index in Shiraz during 2011-2013. I Environ Health Eng. 2016;3(3):182-92. doi: 10.18869/acad- pub.jehe.3.3.182.

24. Allahyari S, Assadi SN, Esmaily H. [Assessment of air pollution condition and comparison of different areas of Mashhad in winter 2011]. J North Khorasan Univ Med Sci. 2014;6(1):7-16. Persian. doi: 10.29252/jnkums.6.1.7.

25. Hosseini G, Teymouri P, Giahi O, Maleki A. [Health Risk assessment of heavy metals in atmospheric pm10 in Kurdistan University of Medical Sciences Campus]. J Mazandaran Univ Med Sci. 2016;25(132):136-46. Persian.

26. Shahsavani A, Naddafi K, Jafarzade Haghighifard N, Mesdaghinia A, Yunesian M, Nabizadeh R, et al. The evaluation of PM10, PM2.5, and PM1 concentrations during the Middle Eastern Dust (MED) events in Ahvaz, Iran, from april through september 2010. J Arid Environ. 2012;77:72-83. doi: 10.1016/j.jaridenv.2011.09.007.

27. Amarloei A, Jonidi Jafari A, Asilian Mahabadi H, Asadollahi K. [The evaluation of PM10, PM2. 5 and PM1 concentration during dust storm events in Ilam city, from Mar 2013 through Feb 2014]. J Ilam Univ Med Sci. 2014;22(4):240-59. Persian.

28. Nasri A, Jebelli B, Nasrabadi T, Hadizadeh H, Ghazanchaei E. [Determining the risk of occupational exposure to benzene and toluene among gasoline station workers, a case study in Kerman]. Occup Med 2015;7(2):57-63. Persian.

29. Heidarinejad Z, Kavosi A, Mousapour H, Daryabor MR, Radfard M, Abdolshahi A. Data on evaluation of AQI for different season in Kerman Iran, 2015. Data Brief. 2018;20:1917-23. doi: 10.1016/j.dib.2018.08.216. [PubMed: 30294644]. [PubMed Central: PMC6171083]

30. Aksu A. Sources of metal pollution in the urban atmosphere (A case study: Tuzla, Istabul). J Environ Health Sci Eng. 2015;13:79. doi 10.1186/s40201-015-0224-9. [PubMed: 26587239]. [PubMed Central: PMC4652336].

31. Mok KM, Tarn SC, Van P, Lam LH. A neural network forecasting system for daily air quality index in Macau. WIT Transact Ecol Environ. 2000;42:822-8.

32. Moattar F, Mikhchi KH, Mohammadzadeh A, Karbasi A, Delbari AS [Determination of heavy metal (lead, cadmium) pollution in air around nuclear power].JEnviron Sci Technol.2008;14(3):37-29. Persian.

33. Yavari H, Saligheh M. Inversion levels in Tehran pollutions. J Appl Res Geogr Sci. 2011;11(20):89-105.

34. Dehghani M, Kamali Y, Shamsedini N, Ghanbarian M. [A study of the relationship between indoor/outdoor particleconcentration in Dena Hospital in Shiraz]. J Health Res Commun. 2015;1(1):49-55. Persian.

35. Mahmoodi Z, Khademi H. [Concentration of selected heavy metals in atmospheric dust of isfahan and neighboring metropolitan areas]. J Water Soil Sci. 2014;18(67):243-55. Persian.

36. Farahmand Kia Z, Mehrasbi MR, Sekhawatju MS, Hasanalizadeh AS, Ramezanzadeh Z. [Study of heavy metals in the atmospheric deposition in Zanjan, Iran]. Iran J Health Environ. 2010;2(4):240-9. Persian.

37. Nazarpur S, Khoramnejadian S, Jozi SA, Saeb K. [Compare the amount of lead and cadmium accumulation of Tehran pine leaves in warm and cold season in Tehran metropolitan (Azadi district)]. Develop Environ. 2015;2:35-44. Persian.

38. Ghanavati N. [Human health risk assessment of heavy metals in street dust in Abadan]. Iran J Health Environ. 2018;11(1):63-74. Persian.

39. Shomali AR, Khodaverdilo H. [Contamination of soils and plants along Urmia-Salmas highway (Iran) to some heavy metals]. I Sci Water Soil. 2012;22:157-72. Persian. 